\title{
Refractory ventricular arrhythmias during aortic valve replacement and cardiac artery bypass requiring 16 attempts of electrical cardioversion: a case report
}

\author{
Mitsuharu Kodaka* (1), Tetsu Mori, Junko Ichikawa, Kazuyoshi Ando and Makiko Komori
}

\begin{abstract}
Background: We report a patient in whom we failed to suppress ventricular fibrillation (VF) using nifekalant but succeeded using amiodarone during cardiopulmonary bypass (CPB).

Case presentation: A 65-year-old male with hemodialysis complained of dyspnea and was diagnosed with aortic valve stenosis and angina pectoris; he was opted for elective aortic valve replacement. When the aortic forceps were declamped during CPB, immediate VF was observed; several attempts of electrical cardioversion (EC) with lidocaine and landiolol and three administrations of nifekalant were temporarily effective. However, the rhythm subsequently changed to torsades de pointes. We administered $2 \mathrm{~g}$ of magnesium sulfate followed by three doses of amiodarone and initiated continuous infusion. Furthermore, we initiated the pacemaker and intra-aortic balloon pumping. These procedures seemed to be effective; the sinus rhythm was sustained until the end of the surgery.

Conclusion: We experienced a cardiac surgery requiring $16 \mathrm{EC}$ attempts to terminate the life-threatening arrhythmias using amiodarone.
\end{abstract}

Keywords: Refractory ventricular fibrillation, Nifekalant, Amiodarone

\section{Background}

Nifekalant, a $\mathrm{K}^{+}$channel blocker available only in Japan, is often used in place of amiodarone for suppressing the signs of life-threatening arrhythmias [1] such as ventricular fibrillation and tachycardia (VF and VT). In our department, nifekalant is the first-choice drug in such situations. It has no inotropic effect and has a short halflife $(1.5-2 \mathrm{~h})$. Amiodarone has been widely used worldwide for treating such lethal arrhythmias through advanced cardiovascular life support (ACLS). There is limited research comparing the use of both these antiarrhythmic agents for resuscitation [2], and the obtained results have not yet confirmed which drug is more excellent for recovery of spontaneous circulation (ROSC) [3].

\footnotetext{
*Correspondence: kmkodaka@cb3.so-net.ne.jp

Department of Anesthesiology \& Intensive Care, Tokyo Women's Medical University Medical Center East, Arakawa-ku, Tokyo 116-8567, Japan
}

Herein, we report a case of a patient where we failed to suppress VF with nifekalant but succeeded with amiodarone, and the patient finally required 16 attempts of electrical cardioversion (EC) and intra-aortic balloon pumping (IABP) after cardiopulmonary bypass $(\mathrm{CPB})$ in cardiac surgery.

\section{Case description}

A 65-year-old male who complained of dyspnea was diagnosed with hypertrophy based on X-ray findings and was hospitalized emergently for an acute heart failure. His past medical history included hypertension and 8 years of hemodialysis treatment due to chronic kidney disease (stage 5GD) by unknown causes. His height and weight were $176 \mathrm{~cm}$ and $55 \mathrm{~kg}$, respectively. His laboratory data were abnormal as follows: C-reactive protein, $1.84 \mathrm{mg} / \mathrm{dl}$; $\mathrm{N}$-terminal pro-brain natriuretic peptide,

\section{Springer Open}

(C) The Author(s). 2020 Open Access This article is licensed under a Creative Commons Attribution 4.0 International License, which permits use, sharing, adaptation, distribution and reproduction in any medium or format, as long as you give appropriate credit to the original author(s) and the source, provide a link to the Creative Commons licence, and indicate if changes were made. The images or other third party material in this article are included in the article's Creative Commons licence, unless indicated otherwise in a credit line to the material. If material is not included in the article's Creative Commons licence and your intended use is not permitted by statutory regulation or exceeds the permitted use, you will need to obtain permission directly from the copyright holder. To view a copy of this licence, visit http://creativecommons.org/licenses/by/4.0/. 
> 35,000 pg/ml; troponin T, $0.111 \mathrm{ng} / \mathrm{ml}$; BUN, $58.2 \mathrm{mg} /$ $\mathrm{dl}$; and $\mathrm{Cr}, 9.2 \mathrm{mg} / \mathrm{dl}$. Cardiothoracic ratio was $63 \%$ based on chest X-ray with butterfly shadow. Electrocardiogram indicated a sinus rhythm, a heart rate of $101 \mathrm{bpm}$, and a QS pattern in V2-3. Transthoracic echo showed the following findings: ejection fraction (EF), 59\%; left ventricular internal dimension in diastole/systole (LVDd/Ds), 57/30 mm; interventricular septum thickness, $20 \mathrm{~mm}$; posterior $\mathrm{LV}$ wall thickness, $15 \mathrm{~mm}$; diameter of left atrium, $56 \mathrm{~mm}$; LV mass index, $201 \mathrm{~g} / \mathrm{m}^{2}$; aortic valve pressure gradient, $104 / 54$ $\mathrm{mmHg}$ (max/mean); aortic valve area, $0.54 \mathrm{~cm}^{2}$; and aortic regurgitation mild, mitral regurgitation mild, and tricuspid regurgitation mild (pressure gradient, $27 \mathrm{mmHg}$ ). The patient's coronary angiography result indicated stenosis of left anterior descending branch \#6, 75\%, and left circumflex coronary artery \#11, 75\%, and computed tomography revealed left-sided pleural effusion. Finally, he was diagnosed with aortic valve stenosis (AS) and angina pectoris, and it was decided to perform elective surgery of aortic valve replacement (AVR) and cardiac artery bypass.

After the initiation of $\mathrm{CPB}$ and aortic clamping, cardiac arrest was induced immediately after cardioplegia infusion and maintained with $500-700 \mathrm{ml}$ infusion every $30 \mathrm{~min}$. Left internal thoracic artery-left anterior descending branch (LITA-LAD) and saphenous vein-right coronary artery (SVG-RCA) anastomoses and AVR (Magna Ease $^{\mathrm{TM}} 23 \mathrm{~mm}$ ) were performed. When the aortic forceps were declamped at 13:57 (marked "A" in Fig. 1), VF occurred immediately as shown in Fig. 1 (anesthetic record). Several attempts of EC with lidocaine (100 and $50 \mathrm{mg}$ ) and landiolol $(2.5-15 \mathrm{mg})$ and three times of administrations of nifekalant $(5-15 \mathrm{mg})$ were temporarily effective at $14: 12-25$ (marked "B"), and the patient ECG suggested sinus rhythm with premature ventricular counts. However, the sinus rhythm and VT occurred alternatively, and the rhythm subsequently changed to torsades de pointes (TdP), which might have occurred because of the overdose of nifekalant at around 14:55 (marked "C"). Therefore, we administered $2 \mathrm{~g}$ of magnesium sulfate followed by amiodarone three times, reaching a total of $450 \mathrm{mg}$ (each dose of $150 \mathrm{mg}$ ), and initiated continuous infusion at $50 \mathrm{mg} / \mathrm{h}$ (c.f. Fig. 1). We also initiated the pacemaker (VVI setting) and IABP at 14:50 and 15:16 (marked "D" and "E"), respectively.

All these procedures appeared to be effective at terminating the VT and subsequently succeeded in weaning from CPB. Thus, the situation with the sinus rhythm was sustained until the end of surgery. During this period, we also took caution to maintain normothermia with no electrolyte imbalance. The flow of the two bypass grafts was assessed using a flowmeter, i.e., LITALAD, $50 \mathrm{ml} / \mathrm{min}$, and SVG-RCA, $9 \mathrm{ml} / \mathrm{min}$. Transesophageal echocardiography revealed only diffuse hypokinesis with approximately $20 \%$ of EF just after aortic declamping, which gradually improved toward the weaning of CPB to approximately $30 \%$ of EF. After admission to the intensive care unit (ICU), the patient showed no VF or VT under the continuous infusion of amiodarone $(50 \mathrm{mg} / \mathrm{h}$ ), and the IABP was withdrawn on postoperative day (POD) 1 and extubated on POD 2. The patient was discharged from the ICU on POD 3 and from the hospital on POD 12 without any complication.

\section{Discussion}

Patients with AS sometimes encounter insufficient cardioplegia because of hypertrophy during CPB. In this case, the patient's condition was also complicated with coronary artery stenosis and hemodialysis, which sometimes tend to calcify the entire artery. The other causes of lethal

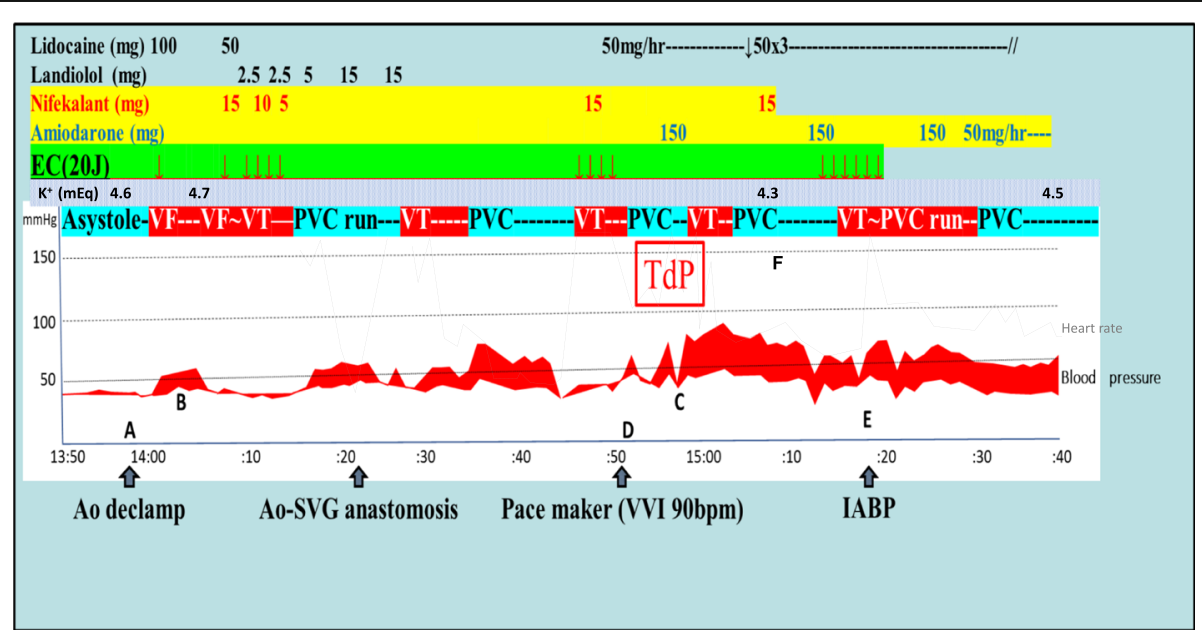

Fig. 1 Treatment details for refractory ventricular arrhythmias occurred after aortic declamp. EC, electrical cardioversion; VF, ventricular fibrillation; VT, ventricular tachycardia; PVC, premature ventricular contraction; PVC run, three or more consecutive PVCs; TdP, torsades de pointes; Ao, aorta; $S V G$, saphenous vein graft; IABP, intra-aortic balloon pumping 
arrhythmias are abnormality of electrodes, hypothermia, and air embolism in coronary arteries. The typical treatments for VF include EC and antiarrhythmic drugs such as $\mathrm{K}^{+}$channel blockers. Nifekalant, a potassium channel blocker, is an antiarrhythmic agent approved in Japan since 1999 [4], induced earlier than intravenous amiodarone, which was also acknowledged in 2007. The advantages of nifekalant are that it is a pure potassium channel blocker and therefore does not cause inotropic effect and that it has a shorter half-life than amiodarone, a multichannel blocker. In contrast, the major drawback is the prolongation of QTs by $>0.55 \mathrm{~s}$ [5] occasionally due to overdose, which can often induce TdP syndrome as occurred in the present case. Although some studies $[2,3]$ show that nifekalant is not inferior to amiodarone in managing patients with fatal ventricular arrhythmias, only a few large-scale studies have compared the efficacy of the two drugs. In fact, a couple of similar case reports published in Japan have described that the majority of VF cases had occurred during coronary reperfusion therapy [6] and in patients undergoing bypass surgery $[7,8]$.

On encountering cases of VF or pulseless VT, nifekalant may be the first choice of treatment for certain anesthesiologists because of its longer history of domestic approval and its basic pharmaceutical advantages, such as faster onset and shorter half-life than amiodarone [2]. Based on their research, Amino et al. [3] reported that it was difficult to conclude which antiarrhythmic agent was more excellent for resuscitation comprising VF or pulseless VT. We inferred that it was difficult to exclude the influences of the pacemaker and IABP for the recovery of the patient. Amiodarone is not only a potassium but also a multichannel blocker and could have been more effective than nifekalant for treating such life-threatening arrhythmia, which had continued for almost $50 \mathrm{~min}$ and required 16 attempts of cardioversion during $\mathrm{CPB}$ weaning.

A limitation of our anesthetic managements was that we should have reduced the doses of nifekalant to approximately $50-60 \%$ while considering hemodialysis [9], even during dilution by $\mathrm{CPB}$. Our study did not measure whether QTc was > $550 \mathrm{~ms}$ when changing treatment from nifekalant to amiodarone. Furthermore, after the occurrence of $\mathrm{TdP}$ at point " $\mathrm{C}$," the administration of nifekalant again should have been avoided as indicated by "F" (around 15:10) in Fig. 1 [10].

\section{Conclusions}

We report a patient in whom we failed to suppress VF using nifekalant but succeeded using amiodarone, and the patient finally required 16 attempts of electrical cardioversion and intra-aortic balloon pumping during $\mathrm{CPB}$ in cardiac surgery.

\section{Abbreviations}

EC: Electrical cardioversion; VF: Ventricular fibrillation; VT: Ventricular tachycardia; IABP: Intra-aortic balloon pumping; CPB: Cardiopulmonary bypass; ACLS: Advanced cardiovascular life support; ROSC: Recovery of spontaneous circulation; AS: Aortic stenosis; AVR: Aortic valve replacement; PVC: Premature ventricular contraction;

TEE: Transesophageal echocardiography; EF: Ejection fraction;

ECG: Electrocardiogram; ICU: Intensive care unit

\section{Acknowledgements}

We thank Enago Editing Service for the English language review.

\section{Authors' contributions}

MK participated in the data collection and writing of the first draft of the manuscript. TM wrote the draft of the manuscript. JI analyzed the data. KA contributed to the data collection. MK provided the final version of the manuscript to be published. The authors read and approved the final manuscript.

\section{Funding}

This research was supported by JSPS KAKEN\# 20 K09230.

Availability of data and materials

Not applicable

Ethics approval and consent to participate

In our institution, the publication of case reports is exempted from ethics committee approval.

\section{Consent for publication}

The patient provided written permission for the authors to publish the report.

Competing interests

The authors declare that they have no competing interests.

Received: 4 July 2020 Accepted: 4 August 2020

Published online: 11 August 2020

\section{References}

1. Guidelines for Drug Treatment of Arrhythmias (JCS 2011) https://www. jstage.jst.go.jp/article/circj/77/1/77_CJ-66-0054/_pdf (accessed on 5/6/2020).

2. Harayama N, Nihei S, Nagata K, Isa Y, Goto K, Aibara K, et al. Comparison of nifekalant and amiodarone for resuscitation of out-of-hospital cardiopulmonary arrest resulting from shock-resistant ventricular fibrillation. J Anesth. 2014;28:587-92.

3. Amino $M$, Inokuchi $S$, Nagao $K$, Nakagawa $Y$, Yoshioka $K$, Ikari $Y$, et al. Nifekalant hydrochloride and amiodarone hydrochloride result in similar improvements for 24-hour survival in cardiopulmonary arrest patients: the SOS-KANTO 2012 study. J Cardiovasc Pharmacol. 2015;66: 600-9.

4. Katoh T, Mitamura H, Matsuda N, Takano T, Ogawa S, Kasanuki H. Emergency treatment with nifekalant, a novel class III anti-arrhythmic agent, for life-threatening refractory ventricular tachyarrhythmias: post-marketing special investigation. Circ J. 2005;69:1237-43.

5. Takenaka K, Yasuda S, Miyazaki S, Kurita T, Sutani Y, Morii I, et al. Initial experience with nifekalant hydrochloride (MS-551), a novel class III antiarrhythmic agent, in patients with acute extensive infarction and severe ventricular dysfunction. Jpn Circ J. 2001;65:60-2.

6. Koizumi T, Komiyama N, Komuro I, Tanigawa T, Iwase T, Ishiwata S, et al. Efficacy of nifekalant hydrochloride on the treatment of life-threatening ventricular tachyarrhythmias during reperfusion for acute myocardial infarction. Cardiovasc Drugs Ther. 2001;15:363-5.

7. Kokaji K, Okamoto M, Hotoda K, Kumamaru H. Experience with nifekalant hydrochloride in a patient with ischemic cardiomyopathy and severe ventricular dysfunction after Dor operation. Jpn Heart J. 2004;45: 691-5.

8. Kurisu K, Hisahara M, Onitsuka H, Sekiya M, Ikeuchi M, Kozai T, et al. Nifekalant hydrochloride terminated electrical storms after coronary surgery. Ann Thorac Surg. 2010;89:1637-9.

9. Miyoishi M, Yasuda S, Miyazaki S, Ueno K, Morii I, Satomi K, Otsuka Y, et al. Intravenous administration of nifekalant hydrochloride for the prevention of 
ischemia-induced ventricular tachyarrhymia in patients with renal failure undergoing hemoedialysis. Circ J. 2003;67:898-900.

10. Kurita T, Noda T, Okamura H, Satomi K, Shimizu K, Suyama K, et al. Clinical use of lintavenous lidocaine, nifelalant and amiodarone for management of lethal arrhythmias. The efficacy and the adverse effect of intravenous nifekalant. Jpn J Electrocardiology. 2009;29:10-7.

\section{Publisher's Note}

Springer Nature remains neutral with regard to jurisdictional claims in published maps and institutional affiliations.

\section{Submit your manuscript to a SpringerOpen ${ }^{\circ}$ journal and benefit from:}

- Convenient online submission

- Rigorous peer review

- Open access: articles freely available online

- High visibility within the field

- Retaining the copyright to your article

Submit your next manuscript at $\boldsymbol{\wedge}$ springeropen.com 